\title{
Hyperinsulinemia Produces both Sympathetic Neural Activation and Vasodilation in Normal Humans
}

\author{
Erling A. Anderson, ${ }^{\star *}$ Robert P. Hoffman," Thomas W. Balon," Christine A. Sinkey, ${ }^{\star}$ and Allyn L. Mark \\ ${ }^{*}$ Departments of Anesthesia, ${ }^{\dagger}$ Internal Medicine, ${ }^{8}$ Pediatrics, and "Exercise Science; and the Cardiovascular and Clinical Research \\ Centers, College of Medicine, The University of Iowa and the Veterans Affairs Medical Center, Iowa City, Iowa 52242
}

\begin{abstract}
Hyperinsulinemia may contribute to hypertension by increasing sympathetic activity and vascular resistance. We sought to determine if insulin increases central sympathetic neural outflow and vascular resistance in humans. We recorded muscle sympathetic nerve activity (MSNA; microneurography, peroneal nerve), forearm blood flow (plethysmography), heart rate, and blood pressure in 14 normotensive males during 1-h infusions of low $\left(38 \mathrm{mU} / \mathrm{m}^{2} / \mathrm{min}\right)$ and high $\left(76 \mathrm{mU} / \mathrm{m}^{2} / \mathrm{min}\right)$ doses of insulin while holding blood glucose constant. Plasma insulin rose from $8 \pm 1 \mu \mathrm{U} / \mathrm{ml}$ during control, to $72 \pm 8$ and $144 \pm 13$ $\mu \mathrm{U} / \mathrm{ml}$ during the low and high insulin doses, respectively, and fell to $15 \pm 6 \mu \mathrm{U} / \mathrm{ml} 1 \mathrm{~h}$ after insulin infusion was stopped. MSNA, which averaged $21.5 \pm 1.5$ bursts/min in control, increased significantly $(P<0.001)$ during both the low and high doses of insulin ( \pm 5.4 and \pm 9.3 bursts/min, respectively) and further increased during 1-h recovery $(+15.2$ bursts $/ \mathrm{min})$. Plasma norepinephrine levels $(119 \pm 19 \mathrm{pg} / \mathrm{ml}$ during control) rose during both low $(258 \pm 25 ; P<0.02)$ and high $(285 \pm 95 ; P$ $<0.01)$ doses of insulin and recovery $(316 \pm 23 ; P<0.01)$. Plasma epinephrine levels did not change during insulin infusion. Despite the increased MSNA and plasma norepinephrine, there were significant $(P<0.001)$ increases in forearm blood flow and decreases in forearm vascular resistance during both doses of insulin. Systolic pressure did not change significantly during infusion of insulin and diastolic pressure fell $\sim$ 4-5 $\mathrm{mmHg}(P<0.01)$. This study suggests that acute increases in plasma insulin within the physiological range elevate sympathetic neural outflow but produce forearm vasodilation and do not elevate arterial pressure in normal humans. (J. Clin. Invest. 1991 . 87:2246-2252.) Key words: insulin • sympathetic nerves • blood glucose • norepinephrine • microneurography $\bullet$ blood pressure
\end{abstract}

\section{Introduction}

Hyperinsulinemia may contribute to increased sympathetic activity and arterial pressure (1-4). For example, epidemiological data indicate a close association between obesity, insulin resistance, hyperinsulinemia, and hypertension $(5,6)$. In addition,

Address correspondence and reprint requests to Dr. Erling A. Anderson, Department of Anesthesia, 301 Medical Laboratories, College of Medicine, University of Iowa, Iowa City, IA 52242.

Received for publication 12 September 1990 and in revised form 15 January 1991.

J. Clin. Invest.

(c) The American Society for Clinical Investigation, Inc.

0021-9738/91/06/2246/07 \$2.00

Volume 87, June 1991, 2246-2252 there is evidence that humans with essential hypertension have insulin resistance and hyperinsulinemia even in the absence of obesity (7). Treatment of hypertension does not reverse the insulin resistance, suggesting that insulin resistance and hyperinsulinemia are not secondary to elevated arterial pressure (8).

Experimental data also associate hyperinsulinemia and elevated pressure. In rats, Edwards and Tipton (9) reported a dose-dependent relationship between increases in insulin (with euglycemia) and increases in arterial pressure. Hyperinsulinemia produced by feeding rats sucrose or fructose has been associated with elevated catecholamine secretion and arterial pressure $(10,11)$

In normotensive humans, Rowe et al. (12) reported that infusing insulin while maintaining normal blood glucose levels (hyperinsulinemic/euglycemic clamp) resulted in dose-dependent increases in plasma norepinephrine levels. In addition, elevating plasma insulin levels to $400-500 \mu \mathrm{U} / \mathrm{ml}$ significantly increased arterial pressure.

Elevated plasma norepinephrine during insulin infusion could reflect increased sympathetic nerve activity, facilitated norepinephrine release from nerve terminals, decreased neuronal reuptake, or altered peripheral metabolism of norepinephrine (13). Experiments in animals demonstrate that insulin can increase sympathetic neural outflow by altering glucose metabolism in ventromedial hypothalamic neurons (14). An effect of insulin on central neural outflow in humans is suggested by observations of Berne et al. (15). They reported that oral ingestion of $100 \mathrm{~g}$ D-glucose produced increases in muscle sympathetic nerve activity that correlated with increased plasma insulin levels.

This study was designed to determine $(a)$ whether acute elevations in plasma insulin increase sympathetic nerve activity to skeletal muscle in the absence of hypoglycemia and $(b)$ if changes in sympathetic activity were accompanied by corresponding changes in vascular resistance. We directly recorded muscle sympathetic nerve activity and measured forearm blood flow and vascular resistance in normotensive volunteers during two sequential doses of insulin infusion, while maintaining blood glucose at control levels (euglycemic clamp).

The distinctive feature of this study was the measurement of sympathetic nerve activity and forearm vascular resistance during elevations of plasma insulin to within the postprandial physiological range with constant blood glucose levels.

\section{Methods}

\section{Subjects}

Subjects were 14 healthy males with a mean age of $20.7 \pm 0.3 \mathrm{yr}$ (mean \pm SE; range 19-22), weight of $83.3 \pm 3.7 \mathrm{~kg}$ (range $68-117$ ) and body mass index (weight/height ${ }^{2}$ ) of $25.1 \pm 0.9$ (range 21-32). None were receiving medications, and all had normal electrocardiograms, urinalysis, blood counts, electrolytes, and renal and liver function. In- 
stitutional Review Board on Human Investigation approval and written informed consent were obtained.

\section{Measurements}

Heart rate was calculated from an electrocardiogram and blood pressure was recorded by automatic sphygmomanometer (Life Stat 200 Physio Control Corp., Redmond, WA). Forearm blood flow was measured by venous occlusion plethysmography using an air cuff plethysmograph (16). Central venous pressure was measured from a catheter inserted into an antecubital vein and advanced into an intrathoracic vein.

Microneurography. Intraneural recording techniques (microneurography) were used to obtain multifiber recordings of postganglionic muscle sympathetic nerve activity. A tungsten microelectrode $(200 \mu \mathrm{m}$ diameter shaft; $1-5 \mu \mathrm{m}$ uninsulated tip) was inserted into a muscle fascicle of the peroneal nerve posterior to the fibular head. A reference electrode was inserted subcutaneously $1-3 \mathrm{~cm}$ from the recording electrode. Electrodes were connected to a preamplifier (gain: 1,000) and amplifier (variable gain: $30-80$ ). Neural activity was fed to a band pass filter (band width: $0.7-2.0 \mathrm{~Hz}$ ) and a resistance-capacitance integrating network (time constant: $0.1 \mathrm{~s}$ ) to obtain a mean voltage neurogram.

Three criteria indicated acceptable recordings of muscle sympathetic nerve activity. First, electrical stimulation $(2-3 \mathrm{~V}, 0.2 \mathrm{~ms}, 1 \mathrm{~Hz})$ through the electrode in the nerve elicited muscle contractions but not paresthesias in the distal extremity. Second, tapping or stretching innervated muscle elicited afferent mechanoreceptor discharges, whereas stroking the skin did not. Third, the neurogram revealed spontaneous, intermittent, pulse-synchronous bursts that increased during held expiration and the Valsalva maneuver. Evidence that this activity represents efferent sympathetic nerve activity includes: $(a)$ interruption of the activity by local nerve block proximal, but not distal, to the recording site; $(b)$ elimination of activity by ganglionic blockade; and $(c)$ a conduction velocity approximating $1 \mathrm{~m} / \mathrm{s}(17,18)$. Neurograms with cutaneous sympathetic activity (assessed by the response to arousal stimuli which elicit single bursts of cutaneous sympathetic activity) were rejected.

Hyperinsulinemic/euglycemic clamp. Insulin (Humulin; Eli Lilly \& Co., Indianapolis, IN) diluted in saline with $1 \mathrm{ml}$ of subject's blood was infused by digital infusion pump (Bard Medsystems, North Reading, MA). Infusion rates were targeted to produce low $(75 \mu \mathrm{U} / \mathrm{ml})$ and then high $(150 \mu \mathrm{U} / \mathrm{ml})$ plasma insulin levels. Each was maintained for $1 \mathrm{~h}$ at either level. The $75-\mu \mathrm{U} / \mathrm{ml}$ level was attained according to the technique of De Fronzo et al. (19) with an initial 10-min priming infusion followed by $50 \mathrm{~min}$ of infusion at $38 \mathrm{mU} / \mathrm{min}$ per $\mathrm{m}^{2}$. The $150-\mu \mathrm{U} / \mathrm{ml}$ plasma insulin level was achieved by a 10 -min priming infusion followed by $50 \mathrm{~min}$ of infusion at $76 \mathrm{mU} / \mathrm{min}$ per $\mathrm{m}^{2}$.

Blood glucose levels were maintained at control levels by variable infusion of $20 \%$ dextrose diluted in saline using an infusion pump (Flo-Gard 6200; Travenol Laboratories, Deerfield, IL). When the insulin infusion was stopped, the glucose infusion was tapered until no longer required to maintain normal glucose levels.

\section{Procedures}

Subjects were placed in the supine position and instrumented for measurement of heart rate, blood pressure, and respiration. Intravenous catheters were placed in the right and left antecubital fossae for $(a)$ insulin/glucose infusion, $(b)$ obtaining blood for glucose, insulin, and catecholamine analysis, and $(c)$ measurement of central venous pressure. Forearm blood flow was measured in the right arm. A satisfactory sympathetic nerve recording site was then achieved. After instrumentation, $20 \mathrm{~min}$ of control measurements were taken. The hyperinsulinemic/euglycemic clamp was then performed as described above. Sympathetic nerve activity and hemodynamic measurements were recorded for 5 of every $10 \mathrm{~min}$ throughout the study. Plasma norepinephrine and epinephrine were measured during control and after $50 \mathrm{~min}$ of both low and high dose insulin, and after $50 \mathrm{~min}$ of recovery. Plasma potassium levels were measured during control and at the end of the study.

\section{Assays}

Blood glucose was analyzed by YSI glucose analyzer (model 27; Yellow Springs Instruments, Yellow Springs, $\mathrm{OH}$ ). Plasma insulin levels were measured in duplicate using the radioimmunoassay described by $\mathrm{Ya}$ low and Berson (20). Inter- and intra-assay coefficients of variation were 9.4 and $5.3 \%$, respectively.

Plasma norepinephrine and epinephrine were assayed by HPLC with electrochemical detection using a Biophase ODS column (Bio Analytical Systems, West Lafayette, IN). In our laboratory this assay has a detection threshold of $18 \mathrm{pg} / \mathrm{ml}$ and inter- and intra-assay coefficients of variation of 7.7 and $7.1 \%$, respectively.

\section{Statistical analyses}

Sympathetic neurograms and electrocardiograms were recorded on a physiological recorder (model 2800S; Gould Inc., Cleveland, OH) at a paper speed of $5 \mathrm{~mm} / \mathrm{s}$. Sympathetic bursts were identified by inspecting mean voltage neurograms. Burst amplitude was measured by inspection. Sympathetic nerve activity was expressed as bursts per minute and as integrated activity (bursts/min $\times$ mean burst amplitude; expressed in arbitrary units). In our laboratory, interobserver and intraobserver variabilities in identifying bursts average $5.4 \pm 0.5 \%$ (range $0-20 \%$ ) and $4.3 \pm 0.3 \%$ (range $0-14 \%$ ), respectively $(21,22$ ).

Forearm blood flow was expressed as $\mathrm{ml} / \mathrm{min}$ per $100 \mathrm{ml}$ forearm volume. Forearm vascular resistance was calculated by dividing mean arterial pressure by flow and is expressed in units.

The $5 \mathrm{~min}$ of data for sympathetic nerve activity, blood pressure, heart rate, and forearm blood flow collected every $10 \mathrm{~min}$ were averaged to a single value. Plasma insulin and blood glucose levels were determined only every $5 \mathrm{~min}$.

Data were analyzed by repeated-measures analysis of variance (ANOVA) using planned contrasts (control vs. the two insulin infusion periods and the recovery period). Post hoc comparisons were made by Least Squares Means procedure. A 0.05 level of significance was used for statistical tests. Data are presented as mean \pm SE.

\section{Results}

Blood glucose and plasma insulin (Fig. 1). Blood glucose levels averaged $82 \pm 1.5 \mathrm{mg} / \mathrm{dl}$ during the control period (Fig. 1). The maximal variation in blood glucose was $6.7 \mathrm{mg} / \mathrm{dl}(8 \%)$ and $10.0 \mathrm{mg} / \mathrm{dl}(12 \%)$ during the low and high doses of insulin, respectively. Blood glucose levels did not fall during insulin infusion, but the mean value fell below control values during recovery as glucose infusion rate was tapered. Six subjects had blood glucose values of $65 \mathrm{mg} / \mathrm{dl}$ or less (mild hypoglycemia) during recovery, while eight subjects remained above that level throughout recovery.

Plasma insulin averaged $7.6 \pm 0.9 \mu \mathrm{U} / \mathrm{ml}$ during control, $72 \pm 8 \mu \mathrm{U} / \mathrm{ml}$ during the $1-\mathrm{h}$ low dose insulin infusion $(P$ $<0.001$ ), and $144 \pm 13 \mu \mathrm{U} / \mathrm{ml}$ during the high dose of insulin $(P$ $<0.001$ vs. low dose). Insulin levels fell to $15 \pm 6 \mu \mathrm{U} / \mathrm{ml}$ at the end of the recovery period $(P<0.01 \mathrm{vs}$. control).

$M$ values ( $\mathrm{mg} / \mathrm{kg}$ per min of metabolized glucose), calculated from glucose infusion rates during minutes $20-60$ of both low and high doses of insulin infusion, were 7.5 \pm 0.9 and $11.5 \pm 1.1$ respectively.

Muscle sympathetic nerve activity (Figs. 2 and 3). Muscle sympathetic nerve activity (MSNA), ${ }^{1}$ expressed as bursts/min, averaged $21.5 \pm 1.5$ during control. Integrated MSNA, expressed in arbitrary units, averaged $384 \pm 38 \mathrm{U} / \mathrm{min}$.

1. Abbreviations used in this paper: DBP, SBP, diastolic, systolic blood pressure; MAP, mean arterial pressure; MSNA, muscle sympathetic nerve activity. 



Figure 1. Plasma insulin levels (top) and blood glucose (bottom) during hyperinsulinemic/euglycemic clamp. Target insulin levels of 75 and $150 \mu \mathrm{U} / \mathrm{ml}$ were maintained for $1 \mathrm{~h}$ each followed by $1-\mathrm{h}$ recovery. Insulin levels fell during recovery but remained significantly above control levels. Blood glucose was maintained within $12 \%$ during insulin infusion. Blood glucose fell below control levels during recovery as glucose infusion was gradually stopped.

During the low dose insulin infusion, MSNA rose significantly $(P<0.001$; Fig. 3). Follow-up analyses revealed that MSNA did not increase significantly until $20 \mathrm{~min}$ after beginning insulin. There was a significant $(P<0.001)$ linear increase in MSNA during the $1 \mathrm{~h}$ of the low dose.


Figure 3. MSNA expressed as bursts/min (top) and integrated activity (i.e., burst frequency $\times$ mean burst amplitude; bottom). MSNA rose after $20 \mathrm{~min}$ of low dose insulin and continued to rise during both high dose insulin and the 1-h recovery period.

During the high dose insulin infusion, MSNA continued to rise and significantly $(P<0.001)$ exceeded levels attained during the low dose insulin (Fig. 3). As during the low dose of insulin, there was a significant $(P<0.05)$ linear increase in MSNA during the $1 \mathrm{~h}$ of the high dose.

MSNA continued to rise during recovery and significantly $(P<0.001)$ exceeded levels during the high dose of insulin.

\section{Control}



Figure 2. Tracing of integrated neurogram of MSNA in one subject during control period and $50 \mathrm{~min}$ after start of the low dose insulin infusion. Plasma insulin rose from 7 $\mu \mathrm{U} / \mathrm{ml}$ during control to $52 \mu \mathrm{U} / \mathrm{ml}$ during infusion of insulin, while blood glucose remained relatively unchanged. MSNA increased markedly during insulin infusion. Despite the increased MSNA, mean blood suovect 0.m. 1214w pressure declined by $4 \mathrm{mmHg}$. 
This continued increase occurred as plasma insulin levels were returning towards control. The increase in MSNA during recovery was not due to hypoglycemia because analysis of data from eight subjects whose blood glucose remained above $65 \mathrm{mg} / \mathrm{dl}$ throughout recovery show comparable and significant increases in MSNA.

Plasma catecholamines and potassium. Plasma norepinephrine, measured in 10 subjects, rose from $199 \pm 19 \mathrm{pg} / \mathrm{ml}$ during control to $258 \pm 25(P<0.02)$ and $285 \pm 95 \mathrm{pg} / \mathrm{ml}(P<0.01)$ after $50 \mathrm{~min}$ of the low and high doses of insulin, respectively (Table I). Norepinephrine levels remained elevated (316 \pm 23 $\mathrm{pg} / \mathrm{ml})$ after $50 \mathrm{~min}$ of recovery $(P<0.01)$.

Plasma epinephrine levels $(28 \pm 5 \mathrm{pg} / \mathrm{ml}$ during control $)$ did not increase significantly during low or high dose insulin infusion ( $35 \pm 6.7$ and $33 \pm 5 \mathrm{pg} / \mathrm{ml}$, respectively). Epinephrine levels increased to $62 \pm 15 \mathrm{pg} / \mathrm{ml}$ during recovery $(P<0.05$ vs. control) but with marked variability across subjects. This variability may have reflected the mild hypoglycemia in some subjects while glucose infusion was tapered.

Serum potassium levels fell slightly from $3.9 \pm 0.01 \mathrm{meq} /$ liter during control to $3.6 \pm 0.01 \mathrm{meq} / \mathrm{liter}$ at the end of insulin infusions $(P<0.01)$ but remained within the normal range.

Blood pressure, central venous pressure, and heart rate (Fig. 4). Systolic blood pressure (SBP) did not change significantly during the low dose of insulin (Fig. 4). In contrast, both diastolic blood pressure (DBP) and mean arterial pressure (MAP) declined slightly $(\sim 3-4 \mathrm{mmHg})$ but significantly $(P<0.001)$. The decrease in DBP was significant within 10 min of starting the insulin infusion as determined by followup analyses.

During the high dose of insulin both DBP and MAP remained significantly $(P<0.001)$ below control values while SBP did not differ significantly from control.

During recovery, SBP was not significantly different from control. However, both DBP and MAP remained below control levels throughout recovery $(P<0.001)$.

Heart rate rose significantly during the low and high doses of insulin $(P<0.001$ vs. control). Followup tests indicated no significant increase until $20 \mathrm{~min}$ into the low dose insulin infusion. Heart rate remained significantly above control values during recovery and exceeded levels observed during high dose insulin infusion $(P<0.01)$.

As measured in five subjects, central venous pressure decreased from $4.6 \pm 0.7 \mathrm{mmHg}$ during control to maximum lows of $3.8 \pm 0.8 \mathrm{mmHg}$ during both low and high doses of insulin and $3.7 \pm 1.2 \mathrm{mmHg}$ during recovery. While the mean decline was significant $(P<0.05)$, central venous pressure increased slightly in two of the five subjects $(+1.3$ and $+0.8 \mathrm{mmHg})$.

Forearm blood flow and vascular resistance (Fig. 5). Fore-

Table I. Plasma Catecholamines

\begin{tabular}{lcccc}
\hline & \multicolumn{4}{c}{ Time } \\
\cline { 2 - 5 } \multicolumn{1}{c}{ Variable } & Control & $\begin{array}{c}\text { Low dose } \\
\text { insulin }\end{array}$ & $\begin{array}{c}\text { High dose } \\
\text { insulin }\end{array}$ & Recovery \\
\hline \multicolumn{1}{c}{$p g / m l$} & & & & \\
Norepinephrine & $199 \pm 19$ & $258 \pm 25^{\dagger}$ & $285 \pm 95^{\dagger}$ & $316 \pm 23^{\dagger}$ \\
Epinephrine & $28 \pm 5$ & $35 \pm 7$ & $33 \pm 5$ & $62 \pm 15^{\dagger}$
\end{tabular}

* Values are mean \pm SE. ${ }^{\dagger} P<0.05$ vs. control.


Figure 4. Systolic, diastolic, and mean blood pressures (top) and heart rate (bottom) during control, low and high dose insulin infusion, and recovery. Systolic pressure did not change significantly during the study. In contrast, diastolic and mean pressures declined significantly at $10 \mathrm{~min}$ of low dose insulin and remained below control levels during both high dose insulin and recovery. Heart rate increased after 20 min of low dose insulin and continued to rise during high dose insulin and recovery periods.

arm blood flow was measured in six subjects. Forearm blood flow significantly exceeded control values during the low dose of insulin $(P<0.001)$. There was a significant linear increase in forearm blood flow over the $1 \mathrm{~h}$ of the low dose of insulin $(P$ $<0.01$ ). Forearm blood flow continued to increase during infusion of the high dose of insulin and exceeded levels during the low dose $(P<0.001)$. However, there was no significant linear change in forearm blood flow during the second level of insulin infusion. Forearm blood flow remained elevated compared with control throughout the $1-\mathrm{h}$ recovery $(P<0.001)$.

Forearm vascular resistance (FVR) declined significantly $(P<0.001)$ during the low dose of insulin. FVR decreased linearly throughout the low dose $(P<0.001)$. FVR did not decrease further during the $1 \mathrm{~h}$ of the high dose of insulin. FVR remained below control values throughout the 1-h recovery period.

Vehicle control experiments. In the experiments involving insulin infusion, an average of $546 \pm 38 \mathrm{ml}$ was infused over $3 \mathrm{~h}$. Approximately $105 \mathrm{ml}$ were withdrawn over this time. Thus, the net volume infusion was $\sim 440 \mathrm{ml}$. To determine whether the volume infusion could have caused the reductions in fore- 



Figure 5. Forearm blood flow and vascular resistance (measured in six subjects). Forearm blood flow rose and vascular resistance declined during the $1 \mathrm{~h}$ low dose insulin infusion. Flow and resistance stabilized during the high dose infusion and remained stable during the $1-\mathrm{h}$ recovery period.

arm vascular resistance, three subjects returned for measurement of forearm blood flow and vascular resistance while receiving an infusion of normal saline in the volume and timing they received during insulin clamp session. Volume infusion was not accompanied by appreciable changes in blood pressure, forearm blood flow, and resistance, specifically: mean blood pressure increased by $3.3 \pm 1.5 \mathrm{mmHg}$; forearm blood flow increased by $0.5 \pm 0.2 \mathrm{ml} / \mathrm{min}$ per $100 \mathrm{ml}$; and forearm vascular resistance decreased by $-3.5 \pm 1.1 \mathrm{U}$ over the 3 -h volume infusion experiments. The reduction in resistance during vehicle infusion was considerably less than that observed during insulin infusion.

\section{Discussion}

The major new finding of this study is that in normal humans, acute increases in plasma insulin levels within the physiologic range produced substantial increases in muscle sympathetic nerve activity but caused vasodilation in the forearm and lowered diastolic blood pressure. These effects were observed in the absence of hypoglycemia.

Potential limitations of study. We did not perform a separate time and vehicle control experiment for all subjects. However, time and vehicle would not seem to account for the findings. First, in three subjects, infusion of vehicle in the amounts used during insulin clamp study did not change forearm blood flow or vascular resistance. Second, in previous studies in our laboratory, MSNA recorded over similar time periods was not accompanied by the significant increases in MSNA seen in this study $(20,21)$. Finally, increase in blood volume associated with vehicle infusion should reflexly decrease, not increase, MSNA.

We measured blood flow and vascular resistance in the forearm while MSNA was recorded in the leg. While MSNA, recorded simultaneously from the radial nerve (arm) and peroneal nerve (leg), is remarkably similar under most conditions (20), differences have been reported under a few conditions such as mental stress (21). Thus, we cannot exclude the possibility that insulin differentially effects MSNA or vascular resistance in arm and leg.

Finally, we recorded sympathetic nerve activity to muscle and cannot extrapolate the results to sympathetic nerve activity to other vascular beds.

Mechanisms of increases in MSNA. Possible mechanisms for the effects of insulin on MSNA include $(a)$ altered blood glucose, $(b)$ baroreflex mediated increases secondary to decreases in blood pressure, and $(c)$ central nervous system actions.

Changes in blood glucose cannot explain the increased MSNA during infusion of insulin. Except during recovery, glucose levels never fell below control values. While blood glucose during the high insulin dose significantly exceeded control values, this slight elevation would not appear to account for increased MSNA during infusion of insulin for two reasons. First, MSNA increased during the low insulin dose when blood glucose values remained constant. Second, Berne et al. (13) have reported that intravenous administration of D-glucose does not markedly increase MSNA in humans.

There were small and inconsistent changes in central venous pressure during insulin. Decreases in central venous pressure can increase MSNA by decreasing cardiopulmonary baroreceptor inhibition of MSNA. However, in three subjects, MSNA increased during insulin despite no change or an increase in central venous pressure.

Diastolic blood pressure fell $\sim 4 \mathrm{mmHg}$ during insulin infusion. Decreases in diastolic pressure can cause baroreflexmediated increases in MSNA. Thus, the increases in MSNA may represent reflex increases secondary to vasodilation and the slight fall in diastolic pressure. However, several observations suggest that the slight decrease in diastolic pressure is not the sole mechanism for the increased MSNA during insulin. First, there was a lack of parallelism between the changes in blood pressure and MSNA. Specifically, diastolic pressure decreased within $10 \mathrm{~min}$ of the low dose insulin infusion while MSNA and heart rate remained at control levels. Second, diastolic pressure did not decline further after the low dose of insulin while MSNA continued to increase. Third, the change in MSNA expressed as a percentage increase per $\mathrm{mmHg}$ reduction in diastolic pressure $(+46 \%)$ exceeds that previously observed during similar reductions in pressure induced by nitroprusside infusion (22\% and $16 \%)(23)$.

A third possible mechanism for the increases in MSNA is a direct, central neural action of insulin. There is considerable evidence for central neural actions of insulin $(2,24-26)$. Insulin-specific binding sites have been located in the hypothalamus of the rat brain (25), and intraventricular injections of insulin have been shown to increase CNS catecholamine turn- 
over (26). Pereda et al. (27) have shown that infusing insulin into the carotid arteries of dogs, at doses which have no effect when administered systematically, elevate arterial pressure.

Thus, while increases in plasma insulin produced substantial increases in MSNA, the precise mechanisms of the increases in MSNA are not clear and may include baroreflex mechanisms and central neural actions of insulin.

MSNA continued to increase for the one hour recovery after insulin infusion while insulin concentrations were declining. This parallels the report of a continuing rise in plasma norepinephrine levels $30 \mathrm{~min}$ after a similar infusion level (12). There are several possible explanations for this prolonged elevation in MSNA. Insulin may be acting through a nonvascular "third" compartment (28) or may have persisting actions on intracellular events that stimulate MSNA such as glucose metabolism. In addition, hypoglycemia occurred during the recovery period and may have contributed to the increases in MSNA during the recovery period. The possible contribution of hypoglycemia in the recovery period is supported by the rise in plasma epinephrine levels during the recovery period.

Mechanisms of vasodilation. Possible mechanisms of forearm vasodilation observed in this study include $(a)$ a direct local dilator action of insulin and $(b)$ indirect humoral or neural effects of insulin.

A direct, local action of insulin is suggested by the reports that insulin is a nonendothelial-dependent dilator in canine carotid arteries (30). In humans, Creager et al. (30) reported that local intraarterial infusion of insulin caused dose-dependent increases in forearm blood flow and decreases in forearm vascular resistance, consistent with a local dilator action.

However, others have found no evidence for a local vasodilator action of insulin. Natali et al. (31) studied forearm vascular responses to local brachial arterial infusion of insulin. Despite increasing forearm plasma insulin levels to $\sim 125 \mu \mathrm{U} / \mathrm{ml}$, forearm blood flow and vascular resistance did not change. Similarly, Chrisholm et al. (32) reported no change in forearm blood flow during local infusion of insulin in humans.

In summary, the evidence supporting a direct vasodilator effect of insulin is conflicting.

Possible indirect mechanisms underlying the vasodilation during systemic infusion of insulin include humoral and neural mechanisms. Hypoglycemia stimulates adrenal medullary epinephrine release. In addition, insulin has been reported to produce beta-adrenergically-mediated vasodilation (30). While insulin might produce vasodilation by releasing epinephrine and stimulating beta-adrenergic vasodilator mechanisms in skeletal muscle, plasma epinephrine did not increase during insulin infusion in our study. Plasma epinephrine increased during recovery in our study as glucose infusion was tapered, but because this was not associated with a further increase in forearm blood flow, circulating epinephrine would not explain the forearm vasodilation during insulin in our study.

Insulin infused systemically could conceivably promote vasodilation by promoting the release of circulating vasodilator substances besides epinephrine. This possibility has not been tested in this study.

Insulin might also promote vasodilation by activating sympathetic neural vasodilator pathways to skeletal muscle. The increased sympathetic nerve activity to muscle during insulin was at least partly sympathetic vasoconstrictor because increased nerve activity was accompanied by increases in plasma norepinephrine. However, insulin might have produced simul- taneous activation of sympathetic neural vasodilator pathways that overrode the increased sympathetic noradrenergic activity. Sympathetic vasodilator mechanisms, which may mediate reduced forearm vascular resistance, include cholinergic vasodilation $(33,34)$.

In summary, this study and previous studies do not indicate the mechanism of the forearm vasodilation during insulin.

Physiologic significance. It has been hypothesized that insulin elevates arterial pressure through its sympathoexcitatory and antinatriuretic effects. This study indicates that acute increases in plasma insulin produce marked sympathoexcitatory effects in normal humans. However, insulin did not elevate arterial pressure presumably because the pressor actions of insulin are offset by vasodilator actions.

Insulin has been reported to attenuate vascular responses to norepinephrine (35). This effect may contribute to the lack of constriction observed during insulin-induced increases in sympathetic nerve activity and plasma norepinephrine.

Evidence that acute hyperinsulinemia elevates arterial pressure is contradictory. Rowe et al. (12) demonstrated significant elevations in arterial pressure in normotensive males during insulin infusion that resulted in serum insulin concentrations exceeding $400 \mu \mathrm{U} / \mathrm{ml}$. However, concentrations of $150 \mu \mathrm{U} / \mathrm{ml}$ (the maximum concentration in this study) did not significantly increase arterial pressure despite increases in plasma norepinephrine levels (12). This suggests that while acute, supraphysiologic elevations in insulin concentrations may elevate arterial pressure in normal humans, increases within the physiologic postprandial range do not.

Interestingly, Hall et al. (36) reported that chronic (30 day) hyperinsulinemia in dogs did not elevate pressure, even during sodium loading, infusion of norepinephrine, or infusion of angiotensin II.

The effect of elevated blood glucose alone was not evaluated in this study. However, Berne et al. (15) reported that intravenous glucose administration did not elevate sympathetic nerve activity. In contrast, oral glucose did increase sympathetic activity. They hypothesized that insulin was responsible for elevated nerve activity because intravenous glucose (which produced transient increases in blood glucose) did not produce marked elevations in plasma insulin, whereas oral glucose increased plasma insulin markedly. Thus, elevated blood glucose per se does not appear sufficient to trigger increases in sympathetic nerve activity, and blood glucose was maintained constant during insulin infusion in this study.

In summary, this study suggests that in normal humans, increases in plasma insulin produce both pressor (increases in sympathetic nerve activity and norepinephrine) and depressor (vasodilation) actions. With acute increases in plasma insulin within the physiologic postprandial range, these opposing actions appear relatively balanced so that arterial pressure does not increase, indeed it declines slightly.

These observations do not exclude a possible role for hyperinsulinemia in promoting increases in arterial pressure. We speculate that there are several mechanisms by which hyperinsulinemia could contribute to hypertension. First, with higher concentrations of plasma insulin, as might occur in insulin resistant subjects, the pressor actions of insulin might predominate as suggested by the study of Rowe, et al. (12). Second, with insulin resistance which attends android obesity and/or essential hypertension, the balance between the pressor and depressor actions of insulin could be altered in favor of a pressor 
action. In this regard, Lakkso et al. (37) have reported that obese subjects with insulin resistance have attenuated limb vasodilator responses to insulin. In addition, a recent study from our laboratory indicates that spontaneously hypertensive rats have exaggerated adrenal nerve responses to increases in plasma insulin in the absence of hypoglycemia (38). Third, chronic trophic actions of insulin could promote structural vascular changes that contribute to hypertension. However, our study suggests that acute increases in plasma insulin do not increase arterial pressure in normal humans.

\section{Conclusion}

This study indicates that in normal humans, acute increases in plasma insulin within the physiologic range and with constant blood glucose increase sympathetic neural outflow to skeletal muscle but reduce forearm vascular resistance and do not increase arterial pressure.

\section{Acknowledgments}

Supported by National Institutes of Health grants HL-43514, HL44546, HL-24962, and AR-39974; by Veterans Administration Merit Review funds; and by grant RR59 from the General Clinical Research Centers Program, Division of Research Resources, National Institutes of Health.

\section{References}

1. Landsberg, L. 1986. Diet, obesity and hypertension: an hypothesis involving insulin, the sympathetic nervous system, and adaptive thermogenesis. $Q$. $J$. Med. 236:1081-1090.

2. Landsberg, L., and D. R. Krieger. 1989. Obesity, metabolism, and the sympathetic nervous system. Am. J. Hypertens. 2:125S-132S.

3. Reaven, G. M. 1988. Role of insulin resistance in human disease. Diabetes. 37:1595-1607.

4. Marigliano, A., R. Tedde, L. A. Sechi, A. Pala, G. Pisanu, and A. Pacifico. 1990. Insulinemia and blood pressure. Am. J. Hypertens. 3:521-526.

5. Modan, M., H. Halkin, S. Almog, A. Lusky, A. Eshkol, M. Shefi, A. Shitrit, and Z. Fuchs. 1985. Hyperinsulinemia. A link between hypertension, obesity and glucose intolerance. J. Clin. Invest. 75:809.

6. Lucas, C. P., J. A. Estigarribia, L. L. Darga, and G. M. Reaven. 1985. Insulin and blood pressure in obesity. Hypertension. 7:702-706.

7. Bonora, E. I. Zavaroni, O. Alpi, A. Pezzarossa, F. Bruschi, E. Dall'Aglio, L. Guerra, C. Coscelli, and U. Butturini. 1987. Relationship between blood pressure and plasma insulin in non-obese and obese non-diabetic subjects. 1987. Diabetologia. 30:719-723.

8. Shen, D. C., S. M. Shieh, M. T. Fuh, D. A. Wu, Y. D. I. Chen, and G. M. Reaven. Resistance to insulin-stimulated-glucose uptake in patients with hypertension. 1988. J. Clin. Endocrinol. Metab. 66:580-583.

9. Edwards, J. G., and C. M. Tipton. 1989. Influences of exogenous insulin on arterial blood pressure measurements of the rat. J. Appl. Physiol. 67:2335-2342.

10. Fournier, R. D., C. C. Chiueh, I. J. Kopin, J. J. Knapka, D. DiPette, and H. G. Preuss. 1986. Refined carbohydrate increases blood pressure and catecholamine excretion in SHR and WKY. Am. J. Physiol. 250:E381-E385.

11. Hwang, I. S., W. C. Huang, J. N. Wu, L. R. Shian, and G. M. Reaven. Effect of fructose-induced hypertension on the renin-angiotensin-aldosterone system and atrial natriuretic factor. Am. J. Hypertens. 1989;2:424-427.

12. Rowe, J. W., J. B. Young, K. L. Minaker, A. L. Stevens, J. Pallotta, and L. Landsberg. 1981. Effect of insulin and glucose infusions on sympathetic nervous system activity in normal man. Diabetes. 30:219-225.
13. Christensen, N. J. Acute effects of insulin on cardiovascular function and noradrenaline uptake and release. 1983. Diabetologia. 25:377-381.

14. Landsberg, L., and J. B. Young. 1985. The influence of diet on the sympathetic nervous system. In Neuroendocrine Perspectives. E. E. Muller, R. M. MacLeod, and L. A. Frohman, editors. Elsevier Science Publishers. 191-218.

15. Berne, C., J. Fagius, and Niklasson. 1989. Sympathetic response to oral carbohydrate administration. J. Clin. Invest. 84:1403-1409.

16. Siggard-Anderson, J. 1968. Venous occlusion plethysmography on the calf. Dan. Med. Bull. 17:1-68.

17. Hagbarth, K. E., and A. B. Vallbo. 1968. Pulse and respiratory grouping of sympathetic impulses in human muscle nerves. Acta Physiol. Scand. 74:96-108.

18. Delius, W., K. E. Hagbarth, A. Hongell, and B. G. Wallin. 1972. General characteristics of sympathetic activity in human muscle nerves. Acta Physiol. Scand. 84:65-81.

19. DeFronzo, R. A., J. D. Tobin, and R. Andres. 1979. Glucose clamp technique: a method for quantifying insulin secretion and resistance. Am. J. Physiol. 237:E214-E223.

20. Yalow, R. S., and S. A. Berson. 1960. Immunoassay of endogenous plasma insulin in man. J. Clin. Invest. 39:1157-1175.

21. Anderson, E. A., B. G. Wallin, and A. L. Mark. 1987. Dissociation of sympathetic nerve activity to arm and leg during mental stress. Hypertension. 9:III-114-III-119.

22. Anderson, E. A., C. A. Sinkey, W. J. Lawton, and A. L. Mark. 1989. Elevated sympathetic nerve activity in borderline hypertensive humans: evidence from direct intraneural recordings. Hypertension. 14:177-183.

23. Rea, R. F. and M. Hamdan. 1990. Baroreflex control of muscle sympathetic nerve activity in borderline hypertension. Circulation. 82:856-862.

24. Sakaguchi, T., and G. A. Bray. 1987. The effect of intrahypothalamic injections of glucose on sympathetic efferent firing rate. Brain Res. Bull. 18:591595.

25. Van Houten, M., and B. I. Posner. 1983. Circumventricular organs: receptors and mediators of direct peptide hormone action on brain. Adv. Metab. Dis ord. 10:269-289.

26. Sauter, A., M. Goldstein, J. Engel, and K. Ueta. 1983. Effect of insulin on central catecholamines. Brain Res. 260:330-333.

27. Pereda, S. A., J. W. Eckstein, and F. M. Abboud. 1962. Cardiovascular responses to insulin in the absence of hypoglycemia. Am. J. Physiol. 202:249252.

28. Insel, P. A., J. E. Liljenquist, J. D. Tobin, R. S. Sherwin, P. Watkins, R. Andres, and M. Berman. 1975. Insulin control of glucose metabolism in man: a new kinetic analysis. J. Clin. Invest. 55:1057-66.

29. D'Orleans-Juste, P., S. Dion, J. Mizrahi, and D. Regoli. 1985. Effects of peptides and non-peptides on isolated arterial smooth muscles: role of endothelium. Eur. J. Pharmacol. 114:9-21.

30. Creager, M. A., C. S. Liang, and J. D. Coffman. 1985. Beta adrenergic-mediated vasodilator response to insulin in the human forearm. J. Pharm. Exp. Ther. 235:709-714.

31. Natali, A., G. Buzzigoli, S. Taddei, D. Santoro, M. Cerri, R. Pedrinelli, and $\mathrm{E}$. Ferrannini. 1990. Effects of insulin on hemodynamics and metabolism in human forearm. Diabetes. 39:490-500.

32. Chisholm, D. J., G. A. Klassen, J. Dupre, and T. Pozefsky. 1975. Interaction of secretin and insulin on human forearm metabolism. Eur. J. Clin. Invest. 5:487-494.

33. Rowell, L. B. 1981. Active neurogenic vasodilation in man. In Vasodilation. P. M. Vanhoutte, and I. Leusen, editors. 1-17.

34. Sanders, J. S., A. L. Mark, and D. W. Ferguson. 1989. Evidence for cholinergically mediated vasodilation at the beginning of isometric exercise in humans. Circulation. 79:815-824.

35. Alexander, W. D., and R. J. Oake. 1977. The effect of insulin on vascular reactivity to norepinephrine. Diabetes. 26:611-14.

36. Hall, J. E., M. W. Brands, S. D. Kivlighn, H. L. Mizelle, D. A. Hildebrandt, and C. A. Gaillard. 1990. Chronic hyperinsulinemia and blood pressure. Hypertension. 15:519-527.

37. Laakso, M., S. V. Edelman, G. Brechtel, and A. D. Baron. 1977. Decreased effect of insulin to stimulate skeletal muscle blood flow in obese man. $J$. Clin. Invest. 85:1844-1852.

38. Morgan, D. A., T. W. Balon, and A. L. Mark. 1990. Hyperinsulinemia produces exaggerated increases in sympathoadrenal activity in spontaneously hypertensive rats. Hypertension. 16:339. 